\title{
Domestic incorporation of the United Nations Convention on the Rights of Persons with Disabilities in the Marshall Islands
}

\section{Divine Waiti}

The United Nations Convention on the Rights of Persons with Disabilities ('Convention') and its Optional Protocol were adopted on 13 December 2006, and were opened for signature on 30 March $2007 .{ }^{1}$ It was described as 'the highest number of signatories in history to a UN Convention on its opening day'. ${ }^{2}$ Unfortunately, this was less inclusive of the Asia-Pacific countries: the region was considered to have the lowest rate of signatures and ratification of the Convention (UNESCAP 2015). Only three countries in the Pacific (Australia, New Zealand and Vanuatu) have signed the convention at the time it was opened for signature, while most of the Pacific Islands countries became a state party some years later. The Republic of the Marshall Islands ('Marshall Islands') is the most recent Pacific island state to become a party to the Convention on 17 March 2015.

This paper gives an account of the domestic incorporation of the Convention on the Rights of Persons with Disabilities in the Marshall Islands. It is a personal reflection with some critiques and comments on some of the work involved in the process of translation of the Convention into domestic law. It first looks at the accession to the international convention; second, it reviews the formulation of policy which drives legislative measures and social policies; third, it discusses the legislative review and compliance process to finetune the national legislative framework; and fourth, it describes the adoption of a comprehensive non-discriminatory law in compliance with the Convention.

1 United Nations Enable (2015), Convention on the Rights of Persons with Disabilities, available at http://www.un.org/disabilities/default.asp?id=150 (accessed 11 Sept. 2015).

2 Ibid. 


\section{Accession to the Convention}

While signing gives a state the expression of its intention to implement a convention, ratification legally binds a state to implement the convention. Where a state is unable to sign and ratify before the entering into force of the convention, accession would be the next process. For instance, the Republic of the Marshall Islands expressed its consent to be bound by the Convention by depositing its instrument of accession with the Secretary-General of the United Nations in New York after the coming into force of the Convention on 3 May 2008.

The ratification of human rights treaties has been an issue for Pacific Island countries for many years. Recently, the Marshall Islands, during its second Universal Periodic Review, was recommended to implement a number of core human rights treaties. ${ }^{3}$ While some considered it lack of prioritisation for implementation, others said it is a matter of resources allocation to which most Pacific Islands countries are not prepared to obligate (Thomas 2009, 6). The Pacific Island countries, especially the small island developing states like the Marshall Islands, have common features of remoteness, smallness in size and capacities, limited resources, aid dependency and vulnerability to climate change and global economic shocks, and clearly resources allocation is the dominant factor.

Another feasibility factor also for the Marshall Islands is the lack of early interventions to engage both the government and civil society, especially for persons with disabilities, to rally support for ratification. It was in early 2013 a person was designated to the relevant government ministry to develop and implement a national disability inclusive policy for the Marshall Islands. ${ }^{4}$ In 2014, a Disabled Peoples Organization (DPO) was established to empower persons with a disability to contribute to the development and the implementation of a disability strategy, policy and legislation. Following the establishment of the DPO, various consultations on the national policy on disability inclusion were undertaken. In a nutshell, there was clearly a lack of resources and capacity to build, educate and lobby leaders to ratify the Convention at the very early stage of the Convention. It should therefore be

3 (i)International Covenant on Civil and Political Rights and its Optional Protocols;

(ii) the International Covenant on Economic, Social and Cultural Rights and its Optional Protocol; (iii) the Convention on the Elimination of all forms of Racial Discrimination; (iv) the Convention against Torture and its Optional Protocol; (v) the Convention on the Rights of Migrant Workers; (vi) the Convention for the Protection of All Persons from Enforced Disappearance; and (vii) the Convention on the Prevention and Punishment of the Crime of Genocide. UN Human Rights Council (2015), Report of the Working Group on the Universal Periodic Review; the Marshall Islands, UN Doc. A/HRC/30/13 (20 July 2015).

4 Republic of the Marshall Islands National Policy on Disability Inclusive Development 2014-2018, 9 . 
noted that considerable efforts must be taken by donor partners to collaborate and engage early, and must mandate inclusive developments to ratify human rights treaties. $^{5}$

\section{Formulation of national policy}

Article 4 of the Convention affirms that a Government must protect and promote the rights of persons with disabilities in all policies and programmes. The Marshall Islands National Policy on Disability Inclusive Development was developed in 2014. It sets out a twin-track approach of a long-term vision for improving the well-being of those persons with disability, which includes the development of legislation and the building of capacity of persons with disability, and to promote activities that are inclusive for persons with disabilities in areas of employment, education, and health services and other social development. The policy was developed with the technical assistance of the United Nations Economic and Social Commission for Asia and the Pacific (UNESCAP)'s Pacific Office, the Pacific Islands Forum Secretariat and Pacific Disability Forum (PDF). Through this technical assistance, research and various consultations with a range of stakeholders, including persons with disabilities, were undertaken. ${ }^{6}$

Because the policy was formulated prior to the acceding to the Convention, much of the attention was drawn towards social policies and lobbying and supporting the government to accede to the Convention and less focus was on the legislative measures and approaches taken for domestic implementation. More specifically for the present purpose, an ideal policy must have a clear legislative framework that lays out the legislative measures needed for translation into law. It must be strongly supported and endorsed by the government and the relevant stakeholders. Furthermore, taking ownership and initiatives to implement a legislative policy agenda is very critical. In the Marshall Islands, the treaty domestication process was often prolonged due to lack of ownership and initiatives to drive successful implementation.

The social policy frameworks for inclusiveness of persons with disabilities must be clearly outlined as well. The policy must take a 'critical collaboration' approach (Wilkinson 2009, 18); where collaborative efforts must be 'between

5 A similar delay was faced with the ratification and implementation of the UN Convention Against Corruption until the UNDP Sub-regional Office was mandated to support the Pacific Island countries with their ratification process by engaging relevant stakeholders in various consultations and trainings. It was after a workshop was conducted for the Members of the Parliaments, that there was an overwhelming support to ratify the Convention and domesticate it into national laws.

6 Republic of the Marshall Islands National Policy on Disability Inclusive Development 2014-18, 9. 
government and civil society and engages people with disability,' This is especially important in the Pacific where traditional languages, cultural beliefs and practices are usually not in conformity with the exercise of the rights of persons with disabilities (ibid., 18). Moreover, the social policy must have a broad-based framework (ibid., 19). Generally, in the Pacific, including the Marshall Islands, the social policy is always confined within the terms of education, health, employment, housing, or welfare without linkages on how each of these impact on the other. The Republic of the Marshall Islands must move away from the charity approach of treating persons with disabilities to a rights-based policy.

\section{Legislative review and compliance}

By acceding to the Convention, the Marshall Islands commits itself to enact domestic laws by adopting measures to improve the rights of persons with disabilities and to abolish legislation, customs and practices that discriminate against persons with disabilities. To ensure that these laws are in conformity with the Convention, a comprehensive legislative and compliance review is required. At the time the policy was formulated, a legislative review of the existing laws of the Marshall Islands was carried out by the Pacific Islands Forum Secretariat prior to the ratification of the Convention. Like other Pacific Island countries, the Marshall Islands lacked a comprehensive legislation that adopts disability rights measures in conformity with the Convention. This includes the Constitution of the Marshall Islands, which guarantees fundamental rights and freedoms that equally apply to all persons, including persons with disabilities. Only a few pieces of legislation identified provided for specific targeted issues, especially for the social areas of health, education, transport, family and other social policy matters; for instance, a specific provision in the Motor Traffic Act provides for reserved parking space for persons with disabilities.

The legislative compliance review identified several issues that needed addressing. First, the lack of comprehensive non-discriminatory legislation for persons with disabilities that leads to the development of relevant legislation to promote, protect and enforce the rights of persons with disabilities. Second, the little piece-meal legislation identified mainly focused on social protection and benefit provisions in education and employment, and health services for mental illnesses. This is where a paradigm shift is called for in attitudes and approaches to persons with disabilities. The focus and approach should shift to recognise persons with disabilities having and enjoying the same human rights just like any other person. Persons with disabilities should no longer be considered 'objects' of charity in need of social protection but are 'subjects' with rights, who are capable of claiming those rights and making decisions for their lives based on their free and informed consent as well as being active 
members of society. Third, the existing legislation lacks disability friendly terminology. While the Convention emphasises the harmonisation of disability friendly terminology, the common references to persons with disabilities in the laws of the Marshall Islands are 'insane', 'handicap', 'disability', 'physical disability', 'mental disability', 'person suffering from mental disorder', 'mental retardation', 'mental deficiency', 'mental impairment', 'mentally or physically incompetent', 'incompetent', 'mental incapacity', 'mentally incapacitated', 'physically helpless', 'mentally defective' and 'disabled person'. ${ }^{8}$ Article 1 of the Convention defines 'persons with disabilities' to 'include those who have longterm physical, mental, intellectual or sensory impairments which in interaction with various barriers may hinder their full and effective participation in society on an equal basis with others'. Such changes to legislative language must go hand in hand with public awareness and training on disability neutral language and references. Language used in legislation must be used at administrative and practical levels. ${ }^{9}$

The next step in the legislative review is to seek constitutional amendments and consequential amendments to the existing legislation that is not in conformity with the provisions of the Convention. These processes are forthcoming during the writing of this chapter.

\section{Adopting a comprehensive legislation}

While the type of legislation each country should adopt depends on the existing laws and the particular legal system of a State party,,$^{10}$ the Marshall Islands opted to adopt a comprehensive legislation that covers the general provisions of rights of persons with disabilities in Article 3 of the Convention and other specific provisions of the Convention. The Rights of Persons with Disabilities (RPD) Act 2015 ('Act') was introduced to the Parliament (Nitijela) and passed its first reading. It was assigned to a Standing Committee on Judiciary and Government Relations for public consultations. The committee reported its findings to the parliament and the bill was voted on and unanimously adopted on 28 September 2015.

7 The traditional Marshallese approach has been one of caring for disabled family members who are regarded as weak; protecting them from harm and from the possibility of being teased, bullied or mocked. This is at odds with the current approach, which aims to empower persons with disabilities.

8 CRPD Legislative Review (2014), Government of the Marshall Islands with the Assistance of the Pacific Islands Forum Secretariat, 16.

9 Ibid.

10 The legal system of the Marshall Islands is largely influenced by the US legal system, having been a US Trusteeship from 1945 until its independence in 1986, and currently being in free association with the US under the 2004 Compact of Free Association with the US. The country has a unicameral parliamentary system where the Parliamentarians are vested with powers to enact, repeal, revoke or amend any law in force in the Republic. 
The two main purposes stated in the Act are (i) to declare, protect, promote, fulfill and enforce the rights and freedoms of persons with disabilities on an equal basis with others; and (ii) to implement the legal obligations of the Marshall Islands as a State Party to the Convention. ${ }^{11}$ In implementing the legal obligations, the Act adopted the principles contained in Article 3 of the Convention, in relation to persons with disabilities, which are:

a. respect for the inherent dignity, individual autonomy including the freedom to make one's own choices, and independence of persons;

b. non-discrimination;

c. full and effective participation and inclusion in society;

d. respect for difference and acceptance of persons with disabilities as part of human diversity and humanity;

e. equality of opportunity;

f. accessibility;

g. equality between men and women;

h. respect for the evolving capacities of children with disabilities and their right to preserve their identities including the respect for the dignity and value of older persons with disabilities, and respect for the inclusive community-based features of Marshallese culture.

Most of these principles listed above underpin the interpretation of substantive provisions that are outlined in the Act. The Act also elaborates on the recognition given to persons with disabilities to participate fully in all aspects of life including the recognition of equal treatment, protection and benefit of the law, the recognition for active participation in all decision making processes, policies and programs, including those that directly concern them, and recognition of the right to voice their concerns including on: approaches to implementing development; implementation, monitoring and reviewing of policies; legislation; and services to ensure that they effectively meet their requirements. ${ }^{12}$

One of the cornerstones to any legislation on the rights of persons with disabilities is 'reasonable accommodation'. The Convention stipulates that a failure to afford a person reasonable accommodation amounts to discrimination on the basis of disability (UN-DESA et al. 2007, 60). In adopting this provision of the Convention, Section 2 of the Act defines as follows:

In this Act:

a. "reasonable accommodation" means appropriate modifications and adjustments, whether of a rule, a practice, an environment, a requirement or otherwise, in order to ensure the full participation by persons with disabilities in an activity, on an equal basis with others;

11 Section 3(2) of the Rights of Persons with Disabilities (RPD) Act 2015.

12 Section 3(3) of the Rights of Persons with Disabilities (RPD) Act 2015. 
b. the nature and limits of the duty to accommodate must be determined on a case by case basis and include factors such as the accommodation required, the size of the entity involved, and the resources available; and

c. the duty must be reasonable and must not impose a disproportionate or undue burden.

These provisions take account of the principle that if the accommodation required would impose a disproportionate or undue burden on the person or entity expected to provide it, then a failure to do so would not constitute discrimination' (ibid., 60). The proposed legislation for the Marshall Islands sets out the factors that should be taken into account when assessing the reasonable accommodation.

In conclusion, one could deduce from these discussions that the domestication of the Convention is an on-going process for the Pacific Island countries. So far, most of the Pacific Island countries have signed and ratified or have acceded to the Convention. The Marshall Islands, as the most recent in the Pacific to become a State party, has taken a step further (as has Australia and New Zealand), to domesticate its national laws in conformity with the Convention. While some differences may exist in the legal systems of the other Pacific Island countries, the pioneering of this piece of legislation and the involvements in the domestic process in the domestication of the laws for the Marshall Islands, would offer some lessons for other Pacific Island countries. It is highly recommended that domestication of the national laws relating to the rights of persons with disabilities be accomplished for rest of the Pacific Island countries.

\section{Bibliography}

Republic of the Marshall Islands National Policy on Disability Inclusive Development 2014-2018.

Thomas, P. (2009) 'Introduction: disability, disadvantage and development', Development Bulletin 73, pp. 5-9.

United Nations Department of Economic and Social Affairs (UN-DESA) (2007), Office of the United Nations High Commissioner for Human Rights, Inter-Parliamentary Union, 'From Exclusion to Reality: Realizing the Rights of Persons with Disabilities', in Handbook for Parliamentarians on the Convention on the Rights of Person with Disabilities and its Optional Protocol (Geneva: United Nations).

United Nations Economic and Social Commission for Asia and the Pacific (UNESCAP) (2015), Disability: Challenges and Opportunities, available at website http://www.unescap.org/our-work/social-development/disability/ about. (accessed 11 Sept. 2015). 
United Nations Enable (2015) Convention on the Rights of Persons with Disabilities, available at http://www.un.org/disabilities/default.asp?id=150 (accessed 11 Sept. 2015).

United Nations Human Rights Council (2015) Report of the Working Group on the Universal Periodic Review; the Marshall Islands, UN Doc. A/ HRC/30/13 (20 July 2015).

Wilkinson, A. (2009) 'Making disability policy in the Pacific rights-based policy', Development Bulletin 73, pp. 18-21. 